\title{
Peripheral vascular disease in patients with systemic lupus erythematosus*
}

\author{
Joanne McDonald, Jacqueline Stewart, Murray B Urowitz, Dafna D Gladman
}

\begin{abstract}
Patients with systemic lupus erythematosus may develop premature atherosclerosis, notably coronary artery disease. A group of 10 patients with peripheral vascular disease presenting with intermittent claudication or gangrene were studied from a group of 563 patients followed prospectively at the Wellesley Hospital Lupus Clinic. These 10 patients were compared with the next lupus clinic patient matched for age and sex, with respect to demographic characteristics and risk factors.

The patients and controls did not differ significantly in lupus activity criteria count, partial thromboplastin time, the number with antibody to cardiolipin, number receiving steroids or mean steroid dose, family history of atherosclerosis, hyperlipidaemia, smoking, hypertension or use of oral contraceptives. The risk factors for developing peripheral vascular disease were a longer duration of systemic lupus erythematosus and a longer duration of use of steroids. Eight of the $\mathbf{1 0}$ patients had coexistent coronary artery disease or transient ischaemic attack.
\end{abstract}

Rheumatic Disease Unit, The Wellesley Hospital, University of Toronto, Ontario, Canada

J McDonald

J Stewart

M B Urowitz

D D Gladman

Correspondence to:

Dr M B Urowitz,

Rheumatic Disease Unit,

The Wellesley Hospital,

160 Wellesley Street East,

160 Wellesley Street

M4Y 1J3, Canada.

Accepted for publication

8 January 1991

*Presented at the Meeting of the Royal College of Physicians and Surgeons, concurrent with the Northeastern American Rheumatism Association Ottawa, Canada,

September 23-26 1988.

Patients and methods

Patients with peripheral vascular disease were identified from among 563 patients with systemic lupus erythematosus satisfying the American College of Rheumatology criteria. These patients were followed prospectively at the Lupus Clinic of the Wellesley Hospital, University of Toronto, from 1970 to 1987 . Patients were identified from recollection of cases by doctors and by a computer search of the Toronto lupus databank for those patients diagnosed as having coronary artery or cerebrovascular disease.
Peripheral vascular disease was defined as one of intermittent claudication, absent peripheral pulses, gangrene, and angiographic or Doppler evidence of large vessel disease. Vascular disease due to vasculitis was excluded. Patients with peripheral vascular disease were matched tc control subjects who were defined as the next patient of similar age and sex with systemic lupus erythematosus registered at the clinic.

The characteristics of patients and controls were reviewed for age at the diagnosis of peripheral vascular disease, sex, duration of systemic lupus erythematosus to time of diagnosis of peripheral vascular disease, the site involved, presence of angina, myocardial infarction or cerebrovascular disease, vascular surgery performed, and date of death. Lupus activity was assessed by the lupus activity criteria count $^{12}$ at the time of diagnosis of peripheral vascular disease. Renal involvement (red blood cell count $>5 /$ high powered field, proteinuria $>0.5 \mathrm{~g} /$ day, casts, creatinine $>120 \mu \mathrm{mol}$ or abnormal renal biopsy specimen), central nervous system involvement (psychosis, seizures or severe headaches unresponsive to narcotic analgesia) and vasculitis (retinal, vasculitic skin or major organ lesions, and Raynaud's phenomenon) before the diagnosis of peripheral vascular disease were recorded. The partial thromboplastin time at the diagnosis of peripheral vascular disease was noted. Antibodies to cardiolipin were measured by the enzyme linked immunosorbent assay (ELISA) method $^{13}$ using the SELISA anti-cardiolipin IgG antibodies assay kit (Walker Laboratories). The dose and duration of treatment with prednisone was calculated.

The presence of classical risk factors for atherosclerosis was also recorded, including: diabetes (fasting blood sugar $>7.0 \mathrm{mmol} / \mathrm{l}$, two hours after a meal $>11.0 \mathrm{mmol} / \mathrm{l})$; hyperlipidaemia (cholesterol $>7.0 \mathrm{mmol} / \mathrm{l}$, triglycerides $>1.8 \mathrm{mmol} / \mathrm{l})$, or hypertension in the year before diagnosis of peripheral vascular disease, family history of coronary heart disease in a first degree relative and use of oral contraceptives.
Other potential risk factors associated with excess morbidity in patients with systemic lupus erythematosus were assessed in the year prior to the diagnosis of peripheral vascular disease, including pericarditis, myocarditis, endocarditis, and congestive heart failure. The date of assessment for the control patients was the closest date to the date of diagnosis of peripheral exact test and the paired $t$ test were used for statistical analysis. vascular disease in the study group. McNamar's 
Table 1 Peripheral vascular disease in patients with systemic lupus erythematosus. Clinical and laboratory features in patients and controls

\begin{tabular}{|c|c|c|c|c|}
\hline \multirow[t]{2}{*}{ Factor } & \multicolumn{2}{|l|}{ Patients } & \multicolumn{2}{|l|}{ Controls } \\
\hline & Number analysed & Value (\%) & Number analysed & Value (\%) \\
\hline Mean age (years) & 10 & 45 & 10 & $42 \cdot 7$ \\
\hline Duration of SLE (months) & 10 & 112 & 10 & $52 \cdot 2^{*}$ \\
\hline Raynaud's phenomenon & 10 & $4(40)$ & 10 & $1(10)$ \\
\hline Vasculitis & 10 & $3(30)$ & 10 & $i(10)$ \\
\hline Pericarditis & 10 & $1(10)$ & 10 & $1(10)$ \\
\hline Endocarditis & 10 & $0(0)$ & 10 & $0(0)$ \\
\hline Myocarditis & 10 & $0(0)$ & 10 & $0(0)$ \\
\hline PTT (s) & 8 & 32 & 8 & $32 \cdot 2$ \\
\hline LACC & 9 & $0 \cdot 7$ & 10 & 0.8 \\
\hline Antibodies to cardiolipin & 8 & $3(37 \cdot 5)$ & 8 & $2(25)$ \\
\hline Smokers & 10 & $7(70)$ & 9 & $3(33)$ \\
\hline Positive family history & 7 & $1(14)$ & 8 & $0(0)$ \\
\hline Oral contraceptive use & 8 & $2(25)$ & $\stackrel{9}{9}$ & 1 (11) \\
\hline History of hypertension & 8 & $5(63)$ & 10 & $3(30)$ \\
\hline Mean blood pressure $(\mathrm{mm} \mathrm{Hg})$ & 8 & $139 / 93$ & 9 & $130 / 80$ \\
\hline Mean cholesterol concentration (mmol/l) & 6 & $7 \cdot 1$ & 8 & 6.48 \\
\hline Mean triglyceride concentration $(\mathrm{mmol} / \mathrm{l})$ & 6 & $2 \cdot 3$ & 8 & 1.88 \\
\hline Angina & 10 & $5(50)$ & 10 & $0(0)$ \\
\hline Myocardial infarction & 10 & $6(60)$ & 10 & $0(0)$ \\
\hline CHF & 10 & $1(10)$ & 10 & $1(10)$ \\
\hline CVA/TIA & 10 & $1(10)$ & 10 & $0(0)$ \\
\hline Steroid use & 10 & $9(90)$ & 10 & $9(90)$ \\
\hline Mean steroid dose (mg prednisone/day) & 10 & $14 \cdot 2$ & 8 & 15 \\
\hline Mean duration steroid use (months) & 10 & 109 & 9 & $34^{*}$ \\
\hline Deaths & 9 & $2(22)$ & 10 & $0(0)$ \\
\hline
\end{tabular}

${ }^{*} \mathrm{p}<0.05$.

Abbreviations: SLE=systemic lupus erythematosus; PTT=partial thromboplastin time; LACC=lupus activity criteria count; $\mathrm{CHF}=$ congestive heart failure; CVATIA = cerebrovascular accident/transient ischaemic attack.

\section{Results}

PATIENT POPULATION

Ten patients (nine women, one man) with peripheral vascular disease and systemic lupus erythematosus were identified from 563 patients with systemic lupus erythematosus. The average age of the patients at the diagnosis of peripheral vascular disease and the control subjects was not significantly different (patients 45 years, range $21-70$ years; controls 43 years, range $20-66$ years (table 1 )).

\section{CHARACTERISTICS OF PATIENTS WITH SYSTEMIC} LUPUS ERYTHEMATOSUS

The average duration of systemic lupus erythematosus at the time of assessment was significantly longer in patients with peripheral vascular disease compared with the controls (patients 112 months, range 6-228 months; controls 52 months, range $12-120$ months, $\mathrm{p}<0.05)$. Each group had four patients with renal involvement and one with central nervous system disease (table 2) The lupus activity criteria count did not differ significantly between the two groups (patients 0.7 , range $0-3$; controls 0.8 , range $0-3)$. These values suggest inactive disease in the patients. Vasculitis was present in $30 \%$ of the patients and $10 \%$ of the controls and Raynaud's phenomenon in 40 and $10 \%$, respectively; neither was statistically different in the controls. The average partial thromboplastin time was identical for each group (32 s, range 28-38 s). No patient or control had an increased partial thromboplastin time. Three patients and two controls had IgG antibodies to cardiolipin as measured by ELISA. One patient and one control had pericarditis, but myocarditis and congestive heart failure were not found in either group.

Nine patients in each group were receiving prednisone. The average dose was $14 \mathrm{mg}$ (range

Table 2 Peripheral vascular disease in patients with systemic lupus erythematosus. Major organ involvement in patients and controls

\begin{tabular}{|c|c|c|c|c|c|}
\hline Subject & Outcome & Major organ & $\begin{array}{l}\text { Vasculitis of } \\
\text { skin }\end{array}$ & $\begin{array}{l}\text { Vasculitis of } \\
\text { major organ }\end{array}$ & $\begin{array}{l}\text { Raynaud's } \\
\text { phenomenon }\end{array}$ \\
\hline Patient 1 & A & - & - & - & - \\
\hline Control 1 & A & Renal: DPGN & - & - & $-\ldots$ \\
\hline Patient 2 & $\mathbf{A}$ & - & $\bar{n} \ldots$ & - & Positive \\
\hline Control 2 & $\mathbf{A}$ & Renal: DPGN & Positive & - & - \\
\hline Patient 3 & A & & Positive & Possible bowel & Positive \\
\hline $\begin{array}{l}\text { Control } 3 \\
\text { Patient } 4\end{array}$ & $\begin{array}{l}\mathbf{A} \\
\mathbf{A}\end{array}$ & $\overline{\text { Renal: focal }}$ & - & 二 & - \\
\hline & & Segmental GN & & & \\
\hline Control 4 & $\mathbf{A}$ & $\begin{array}{l}\text { Renal: focal } \\
\text { Segmental GN }\end{array}$ & - & - & - \\
\hline Patient 5 & D & Renal: mesangial & - & - & - \\
\hline Control 5 & $\bar{A}$ & CNS: cerebritis & - & - & $\bar{n}$ \\
\hline Patient 6 & $?$ & - & 一 & 一 & Positive \\
\hline Control 6 & $\mathbf{A}$ & Renal: mesangial & - & - & - \\
\hline Patient 7 & $\mathbf{A}$ & Renal: mesangial & - & - & - \\
\hline Control 7 & $\mathbf{A}$ & $\overline{0}$ & - & $\overline{\mathrm{B}}$ & 一 \\
\hline Patient 8 & D & Renal: membranous & - & Retina & 一 \\
\hline Control 8 & A & - & - & - & - \\
\hline Patient 9 & $\mathbf{A}$ & CNS: headache & - & - & Positive \\
\hline Control 9 & A & - & - & - & Positive \\
\hline Patient 10 & A & - & - & - & - \\
\hline Control 10 & A & - & - & - & - \\
\hline
\end{tabular}


Table 3 Peripheral vascular disease in patients with systemic lupus erythematosus. Clinical characteristics

\begin{tabular}{|c|c|c|c|c|c|}
\hline $\begin{array}{l}\text { Patient } \\
\text { no. }\end{array}$ & $\begin{array}{l}\text { Site of } \\
\text { peripheral vascular } \\
\text { disease }\end{array}$ & Symptoms & $\begin{array}{l}\text { Reduced } \\
\text { pulses }\end{array}$ & Studies & Operation performed \\
\hline 1 & Right leg & Pallor, gangrene (toes) & $\begin{array}{l}\text { DP right and left, } \\
\text { PT right and left }\end{array}$ & $\begin{array}{l}\text { Angiogram-extensive } \\
\text { occlusive disease }\end{array}$ & - \\
\hline 2 & Femorals and distal leg & Intermittent claudication & $\begin{array}{l}\text { Left femoral, bilateral } \\
\text { DP, PT }\end{array}$ & Doppler & - \\
\hline 3 & Left calf & $\begin{array}{l}\text { Left intermittent } \\
\text { claudication }\end{array}$ & $\begin{array}{l}\text { Left popliteal, bilateral } \\
\text { DP, PT }\end{array}$ & - & - \\
\hline 4 & Right superficial femoral & $\begin{array}{l}\text { Right thigh, calf, } \\
\text { intermittent claudication }\end{array}$ & Right femoral, DP, PT & Doppler & - \\
\hline 5 & Right leg & $\begin{array}{l}\text { Right intermittent } \\
\text { claudication }\end{array}$ & Bilateral DP, PT & Angiogram & Right aorto-femoral dilatation \\
\hline 6 & Feet & $\begin{array}{l}\text { Leg weakness, ulcer, } \\
\text { right great toe }\end{array}$ & Bilateral DP, PT & - & Right lumbar sympathectomy \\
\hline 7 & $\begin{array}{l}\text { Common iliac superficial } \\
\text { femoral bilateral }\end{array}$ & Intermittent claudication & $\begin{array}{l}\text { Bilateral femoral, } \\
\text { right popliteal, DP, PT }\end{array}$ & $\begin{array}{l}\text { Doppler, angiogram, right } \\
\text { extensive iliac stenosis }\end{array}$ & $\begin{array}{l}\text { Left extensive iliac } \\
\text { angioplasty, aorto-femoral } \\
\text { bypass }\end{array}$ \\
\hline 8 & Femoral, distal legs & 一 & $\begin{array}{l}\text { Bilateral femoral, popliteal } \\
\text { DP, PT }\end{array}$ & - & - \\
\hline 9 & Left subclavian, both legs & $\begin{array}{l}\text { Left arm pain, } \\
\text { intermittent claudication }\end{array}$ & $\begin{array}{l}\text { Bilateral DP, PT, } \\
\text { left arm }\end{array}$ & $\begin{array}{l}\text { Doppler-subclavian, } \\
\text { carotid, angios, } \\
\text { subclavian, carotid }\end{array}$ & Left subclavian carotid bypass \\
\hline 10 & Left iliac & Intermittent claudication & $\begin{array}{l}\text { Right femoral, bilateral PT } \\
\text { Right DP }\end{array}$ & Angiogram & Left iliac endarterectomy \\
\hline
\end{tabular}

Abbreviations: $\mathrm{DP}=$ dorsalis pedis; $\mathrm{PT}=$ posterior tibial.

0-80 mg) for patients with peripheral vascular disease, and $15 \mathrm{mg}$ (range $0-60 \mathrm{mg}$ ) in the controls. The duration of steroid treatment was significantly longer in patients with peripheral vascular disease (109 months, range 0-228) than in controls (34 months, range $0-96 ; p<0.05$ ). There were two deaths in the group of patients with peripheral vascular disease and none in the control group.

\section{CHARACTERISTICS OF PATIENTS WITH PERIPHERAL} VASCULAR DISEASE

The vascular disease involved the legs in all patients, and the subclavian artery in one patient (table 3). All but one had a gradual onset of symptoms. Seven had symptoms of intermittent claudication and two had gangrene or ulcers. Reduced or absent pulses were noted in all patients. Angiograms confirmed the diagnosis in six and Doppler scans in four patients. None of the angiograms had features which suggested vasculitis. Five patients underwent a total of six operations (table 3 ).

CLASSIC RISK FACTORS FOR ATHEROSCLEROSIS

The mean cholesterol concentration in patients with peripheral vascular disease was $7 \cdot 1 \mathrm{mmol} / 1$ compared with $6.48 \mathrm{mmol} / 1$ in controls. This difference was not statistically significant. The triglyceride concentration was $2.3 \mathrm{mmol} / 1$ in patients and $1.88 \mathrm{mmol} / \mathrm{l}$ in controls (not significant). The mean blood pressure was similar in the two groups $(139 / 93 \mathrm{~mm} \mathrm{Hg}$ in patients; $130 / 80$ in controls). There were more patients with a history of hypertension than controls $(63 \mathrm{v} 30 \%)$. Seventy per cent of patients smoked compared with $33 \%$ of controls. Although there was a trend towards an increased incidence of smoking and hypertension in the patient group, the difference was not statistically significant.

The family history of atherosclerosis was known in only seven of the patients and was positive in one (14\%), whereas none of the 10
Table 4 Peripheral vascular disease in patients with systemic lupus erythematosus. Other sites of atherosclerosis

\begin{tabular}{lll}
\hline Patient No. & Site & Manifestation \\
\hline 1 & None & None \\
2 & Cerebrovascular & TIA \\
3 & Cardiac & Angina, MI, ACB \\
4 & Cardiac & MI, ACB \\
5 & Cardiac & Angina \\
6 & Cardiac & MI, Angina \\
7 & Cardiac & MI, ACB \\
8 & Cardiac & Angina, MI \\
9 & None & None \\
10 & Cardiac & Angina, MI \\
\hline
\end{tabular}

Abbreviations: TIA = transient ischaemic attack; $M I=$ myocardial infarction; $\mathrm{ACB}=$ aorto-coronary bypass.

controls had a positive family history for this disease. Previous use of oral contraceptives was found in two of eight patients (25\%) and in only one of nine controls $(11 \%)$. This again was not statistically significant. One of the patients with peripheral vascular disease had a long history of insulin dependent diabetes mellitus, but none of the controls was diabetic.

Five patients had a history of angina and six had a previously documented myocardial infarction. One had a previous transient ischaemic attack diagnosed by classical symptoms. Three patients had undergone an aorto coronary bypass operation for their coronary artery disease; all had a previous myocardial infarction (table 4).

\section{Discussion}

As patients with systemic lupus erythematosus survive longer, the morbidity patterns are changing. ${ }^{6}$ Specifically, atherosclerotic complications involving coronary arteries (angina and myocardial infarction) have been reported. Coronary artery disease due to atherosclersosis in patients with systemic lupus erythematosus was first observed in the early 1970 s. ${ }^{4}$ In fact, it was suggested that the excess of late deaths in systemic lupus erythematosus is due to such complications. ${ }^{5}{ }^{13} \mathrm{~A}$ relationship to the length of disease and duration of corticosteroid treatment has been observed. 
In this clinic population of patients with systemic lupus erythematosus, $41 \%$ of 27 autopsies had evidence of significant atherosclerosis of coronary arteries and the aorta. ${ }^{14}$ This total included patients without clinical features of ischaemic heart disease. Twenty per cent of all deaths were due to vascular events (myocardial infarctions) and 50\% of deaths were in patients who had had systemic lupus erythematosus for more than two years.

Previously we identified 45 patients at our lupus clinic who had angina and myocardial infarctions and found the sytemic lupus erythematosus to be quiescent at the time of the vascular event (by lupus activity criteria count). Compared with the clinic population, an increased incidence of pericarditis, myocarditis, congestive heart failure and hypertension was found in these patients, as well as hyperlipidaemia, hyperglycaemia, diabetes, and increased average cortisone use. ${ }^{6}$ Coronary atherosclerosis is therefore well reported in patients with systemic lupus erythematosus and a relationship with length of disease, duration of corticosteroid use, and other risk factors for atherosclerosis has been noted.

Peripheral vascular disease due to atherosclerosis has only been rarely reported. DePalma $^{15}$ described three patients with well controlled systemic lupus erythematosus who developed symptomatic peripheral vascular disease of the feet which required an operation. The criteria for diagnosis of systemic lupus erythematosus were not given. The patients had been treated with prednisone (5-12 mg daily) for 1-10 years. Two smoked and the results of the operation were good. Apart from this, other reports have been of vasculitis of the foot vessels presenting suddenly and catastrophically, usually with gangrene, and accompanied by very active systemic disease. ${ }^{16} 17$

This study was of 10 subjects who illustrated the general nature of atherosclerosis in patients with systemic lupus erythematosus. In addition to symptomatic peripheral vascular disease, most patients had coronary artery disease. The peripheral vascular disease developed at a younger age in these patients than in the general population. It occurred late in the course of the disease (average 112 months) and was generally associated with inactive sytemic lupus erythematosus. The clinical characteristics of these patients fit a diagnosis of peripheral vascular disease due to atherosclerosis as they had a slow onset of typical symptoms, quiescent systemic lupus erythematosus, and angiograms compatible with atherosclerotic disease.

The classic risk factors for atherosclerosis were not significantly associated with the presence of peripheral vascular disease in these patients. However, a history of hypertension and smoking showed trends towards an increased frequency in those patients with peripheral vascular disease.

Factors significantly related to the development of peripheral vascular disease included duration of systemic lupus erythematosus and duration of corticosteroid use. Previously reported cases of vascular disease in lupus have described acute ischaemia due to vasculitis in patients with active disease. The reason for the development of premature atherosclerosis in patients with systemic lupus erythematosus is not precisely known. Atherosclerosis is classically thought to represent a vascular response to intimal injury occurring in association with well recorded risk factors. ${ }^{18}$ The intimal proliferative lesion may be initiated by endothelial injury with subsequent monocyte attachment to the endothelium, with subendothelial migration leading to the release of growth factors and the formation of fatty streaks. Fatty streaks are ultimately converted to fibrous plaques, and if the endothelium is denuded, platelet attachment occurs. With a further release of growth factors, smooth muscle cells proliferate. Alternatively, subtle endothelial injury without morphological alteration may occur. The endothelium is then stimulated to secrete growth factors and a similar cycle is initiated. This pathway may be important in the development of atherosclerosis in patients with systemic lupus erythematosus. Such endothelial injury may be stimulated in these patients by metabolic factors (hypercholesterolaemia), immunological factors (immune complexes), toxins or, perhaps; viruses.

Another possible factor in the development of peripheral vascular disease may be the presence of antibody to cardiolipin. Antibodies to phospholipids have been recognised in association with ocular occlusive disease ${ }^{19}$ and cerebral ischaemia. ${ }^{20}{ }^{21} \mathrm{An}$ increased risk for peripheral thrombosis has recently been described in patients with the lupus anticoagulant who undergo a vascular operation. ${ }^{22}$ An anticoagulant was not detected in any of our patients or controls. Although three patients had antibodies to cardiolipin, as detected by ELISA, two of the controls also had these antibodies, making it unlikely that they played a role in the development of the peripheral vascular disease.

In conclusion, peripheral vascular disease is part of the spectrum of atherosclerosis in patients with systemic lupus erythematosus and may present as the only manifestation of atherosclerosis. Features significantly associated with the development of peripheral vascular disease in patients with systemic lupus erythematosus include the duration of systemic lupus erythematosus, duration of steroid use, and presence of other sites of atherosclerosis. Peripheral vascular disease in patients with systemic lupus erythematosus is associated with significant morbidity and death. Doctors should consider the diagnosis of peripheral vascular disease in patients with systemic lupus erythematosus with vascular symptoms in the hands and feet.

1 Alarcón-Segovia D, Osmudson P J. Peripheral vascular syndromes associated with systemic lupus erythematosus. Ann Intern Med 1965; 62: 907-19.

2 Ansari A, Larson H P, Henry H D. Vascular manifestation of systemic lupus erythematosus. Angiology 1986; 37: 423-32.

3 Boey M L, Colaco C B, Gharair A E, Eckon K B, Loizon S, Hughes $G \mathrm{~W}$. Thrombosis in systemic lupus erythematosus: striking association with the lupus anticoagulant. Am Med $\mathcal{F}$ 1963; 287: 1021-3.

4 Tsakraklides M D, Blieden L C, Edwards J E. Coronary atherosclerosis and myocardial infarction associated with systemic lupus erythematosus. Am Heart $\mathcal{f}$ 1974; 87: 637-41. 
5 Urowitz M B, Bookman A M, Koehler B E, Gordon D A, Smythe H A, Ogryzlo M A. The bimodal mortality pattern of systemic lupus erythematosus. Am $\mathcal{J}$ Med 1976; 60: 221-5.

6 Gladman D D, Urowıtz M B. Morbidity in systemic lupus erythematosus. F Rheumatol 1987; 14 (suppl 15): 223-6.

7 Haider Y S, Roberts W C. Coronary arterial disease in systemic lupus erythematosus. Am f Med 1981; 70: 775-81.

8 Meller J, Conde C A, Deppisch L M, Donoso E, Dork S. Myocardial infarction due to coronary atherosclerosis in three young adults with systemic lupus erythematosus. $\mathrm{Am}$ f Cardiol 1975; 35: 309-13.

9 Buckley B H, Roberts W C. The heart in systemic lupus erythematosus and the changes induced in it by corticosteroid therapy. Am ₹ Med 1975; 58: 243-63.

10 Homey C J, Liberthson R R, Fallon J T, Gross S, Miller $L$ N. Ischemic heart disease in systemic lupus erythematosus in the young patient with SLE. $\mathcal{F}$ Rheumatol 1983; 10: $464-6$.

11 Spiera H, Rutherberg R. Myocardial infarction in four young patients with SLE. $\mathcal{F}$ Rheumatol 1983; 10: 464-6.

12 Urowitz M B, Gladman D D, Tozman E. The lupus activity criteria count (LACC). I Rheumatol 1984; 11: 783-7.

13 Harris E N, Gharavi A E, Patel S P, Hughes G R V. Evaluation of the anti-cardiolipin antibody test: report of an international workshop held 4 April 1986. Clin Exp Immunol 1987; 68: 215-22.

14 Rubin L A, Urowitz M B, Gladman D D. Mortality in systemic lupus erythematosus: the bimodal pattern revisited. $Q \mathcal{F}$ Med 1985; 55: 87-98.

15 DePalma R G, Moskowitz W, Holden W D. Peripheral ischemia and collagen disease. Arch Surg 1972; 105: 313-8.

16 Keat E C B, Shore J H. Gangrene of the legs in disseminated lupus erythematosus. BMF 1958; 1: 25-7.

17 Gladstein G S, Rynes R I, Parhami N, Bartholomew L E. Gangrene of a foot secondary to systemic lupus erythematosus with large vessel vasculitis. F Rheumatol 1979; 6: 549-53.

18 Russ R. Pathogenesis of artherosclerosis_an update. $N$ Engl f Med 1986; 314: 488-99.

19 Asherson R A, Merry P, Acheson J F, Harris E N, Hughes G R V. Antiphospholipid antibodies: a risk for occlusive occular vascular disease in systemic lupus erythematosus and the 'primary' antiphospholipid syndrome. Ann Rheum Dis 1989; 48: 358-61.

20 Harris E N, Gharavi A E, Asherson R A, Boey M L, Hughes G R B. Cerebral infarction in systemic lupus: association with anticardiolipin antibodies. Clin Exp Rheumatol 1984; 2: 47-51.

21 Asherson R A, Khamashta M A, Gil A, et al. Cerebrovascular disease and antiphospholipid antibodies in systemic lupus erythematosus, lupus like disease and the primary antierythematosus, lupus like disease and the primary ant
phospholipid syndrome. Am $\mathcal{F}$ Med 1989; 86: 391-9.

22 Ahn S S, Kalunian K, Rosove M, Moore W S. Postoperative thrombotic complications in patients with lupus anticoagulant: increased risk after vascular procedures. $\mathcal{F}$ Vasc Surg 1988; 7: 749-56. 